\title{
The role of emotional skills in music education
}

\author{
Emilia A Campayo-Muñoz ${ }^{1}$, Alberto Cabedo-Mas
}

\begin{abstract}
Developing emotional skills is one of the challenges that concern teachers and researchers in education, since these skills promote well-being and enhance cognitive performance. Music is an excellent tool with which to express emotions and for this reason music education should play a role in individuals' emotional development.

This paper reviews the results of previous studies that explore the connections between active engagement with music and the development of emotional skills, specifically in the field of music education. A sample of 21 investigations was analysed.

The results from the selected studies show that music has multiple benefits for the development of certain aspects of emotional skills and positive implications for education. Suggestions for music educators gathered from the previous research are presented and potential areas of interest for further exploration in the field are identified.
\end{abstract}

\section{Keywords}

Music education, emotional skills, music training, music teaching, emotional development.

Universitat Jaume I de Castellón, Spain

${ }^{1}$ Corresponding Author:

Emilia Ángeles Campayo Muñoz, Av. Cataluña, 9, Puzol, Spain.

Email: ecmapayo@uji.es 


\section{Introduction}

Research on knowledge of one's own emotions and how to manage them properly has been present in the literature for several decades (Greenspan, 1989; Leuner, 1966). However, it was in 1990 that Salovey and Mayer (1990) introduced the construct of emotional intelligence (EI) in its present form, which generated keen research interest in the psychological causes and effects of EI. In their study, Salovey and Mayer identified the concept of emotional intelligence as "the ability to monitor one's own or others' feelings and emotions, to discriminate among them and to use this information and to

guide one's thinking and actions" (Salovey \& Mayer, 1990, p.189). In 1995, Daniel Goleman spread awareness of this concept through his book Emotional Intelligence. The concept of emotional skill is derived from emotional intelligence and is understood as the ability to apply emotional intelligence to everyday life (Bisquerra \& Pérez, 2007).

According to the studies by Salovey and Mayer (1990) and Goleman (1995), learning emotional skills promotes individuals' mental balance, which has positive implications for health, well-being and good performance. The need for emotional education was therefore identified (Bisquerra, 2003; Fernández-Berrocal \& Extremera, 2002), leading to the creation of the Consortium for the Advancement of Social and Emotional Learning (CASEL) in 1994. The main objective of this organisation is to 
promote and implement social and emotional learning as an integral part of teaching in schools (Bisquerra, 2003).

Music is an ideal vehicle for working with emotions because of the natural connection between the two (Pellitteri, Stern \& Nakhutina, 1999, p. 25). The influence and effects of music on emotion have been explored in different times and from diverse perspectives (e.g., Bennet, 1942; Juslin \& Sloboda, 2001; Meyer, 1956). They were matters of concern for major philosophers of ancient Greece such as Plato or Aristotle (Rachmawati, 2010; Salappa-Liopoulou, 2012); and in acknowledging an ability to influence people's behaviour and morality, music was part of ethos theory (Sastre, 2014). Consistent with the Baroque doctrine of affections (Harnoncourt, 1988), many authors upheld that both composers and performers have the capacity to use musical elements to bring out certain emotions in the listener (Juslin, 2003). The link between music and emotion has therefore had an impact on educational activity, especially on teaching and learning music. Recently, emotional education has attracted increasing interest in formal education settings, in both primary and secondary schools, although the literature exploring models and effects of working with emotions and musical education is scarce.

According to David Elliott (2005), identifying emotions when we listen to music and expressing them when we play a musical instrument are not usually spontaneous events. Only by developing and being aware of emotions can they be identified 
naturally and automatically. It is precisely this awareness of emotions that leads to emotional development. In this line, Resnicow, Salovey and Repp (2004) argue that there is a positive correlation between recognition of emotions in performances of classical piano music and levels of emotional intelligence. Musical education may therefore be a useful tool for emotional development. The present systematic review was motivated by (1) the absence, to our knowledge, of previous studies that brought together the scientific literature in the field of music education and emotional development, and that had reviewed the findings of former studies, (2) the lack of methodological connections between the investigations undertaken, and (3) the absence of research that evaluated and systematised intervention protocols to promote the enhancement of emotional development through music, and also the lack of studies on the effects of teaching emotional skills for musical performance.

The methodological classification and assessment of the research examined in this paper enabled the authors to draw some general conclusions from the results of the studies analysed and to identify research strategies where there may be a gap in the literature. 


\section{Methods}

\section{Search Criteria}

PRISMA guidelines for conducting systematic reviews (Moher, Liberati, Tetzlaff, \& Altman, 2009) were followed in the review process. The studies, all of which were published in scientific journals, were selected using the Scopus, ERIC and Web of Science electronic databases.

Considering the limited literature specifically on music education and the development of emotional skills, generic descriptors were used to ensure a greater inclusion of potential articles dealing with the subject either directly or indirectly. The descriptors used, in different combinations, were music, music education, emotion, emotional skills and emotional intelligence. The initial filters applied related to language (only articles in English), study area (publications from the fields of psychology, social sciences and arts and humanities) and the search period. Since the construct of emotional intelligence was not defined in its present form until 1990, only studies published since that year were considered.

\section{Selection of studies}

Two inclusion criteria were established to select the studies: first, the relationship between emotional development and music education, understood as a general framework, and second, the relationship between emotional development and playing a 
musical instrument. Studies were excluded whose research samples consisted of people only listening to music with no active instrumental or singing practice, or those combining or comparing performing and listening. The two authors initially carried out the process of selecting studies independently. Where disagreement arose over the inclusion of an article, a joint decision was reached after further discussion.

The initial sample included 1,934 articles, which were assessed and ruled out according to the diagram below (Figure 1).

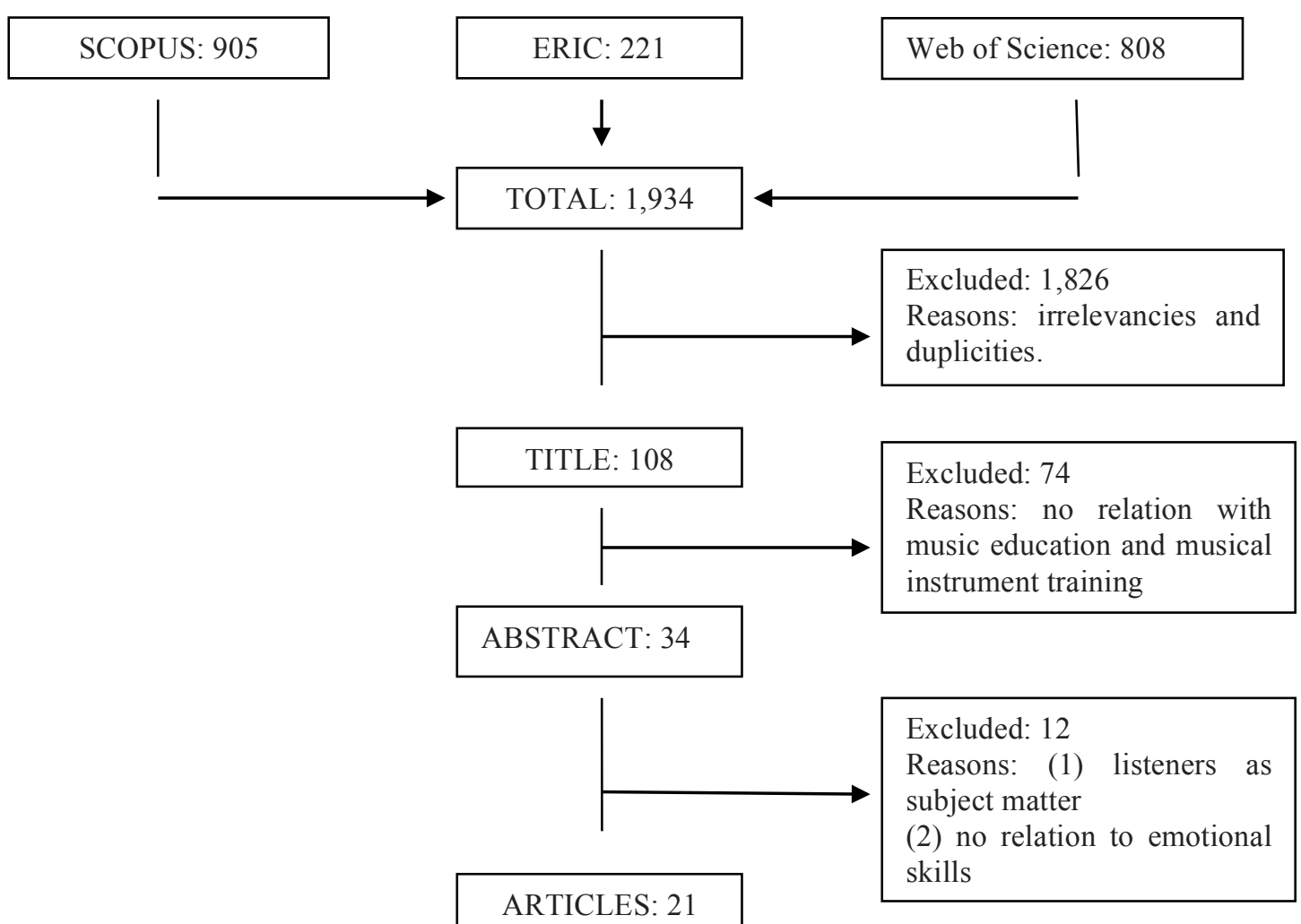


Of these initial 1,934 studies, only 21 were selected for analysis (Table 1). These articles were classified into the areas of (1) basic research and (2) interventions. The second classification was then sub-divided into articles that (3) address issues connected to music education and its benefits in the emotional field, and those that (4) study the connection between playing a musical instrument in itself and its benefits in the emotional field. Articles dealing directly with (5) the development of emotional skills were taken into account. Finally, we distinguished between research focussing (6) on cognitive-behavioural and (7) neuroscience aspects. Based on the premise that the acquired knowledge generates a new thinking structure, the cognitive-behavioural approach studies behavioural changes related to playing a musical instrument. The neuroscience approach explores developments produced by learning a musical instrument, and how these developments influence, at the same time, an individual's behaviour. 


\begin{tabular}{|c|c|c|c|c|c|c|c|}
\hline & (1) Intervention & (2) Basic research & $\begin{array}{l}\text { (3) General music } \\
\text { education }\end{array}$ & $\begin{array}{l}\text { (4) Instrumental } \\
\text { practice }\end{array}$ & $\begin{array}{l}\text { (5) Development } \\
\text { of emotional } \\
\text { skills }\end{array}$ & $\begin{array}{c}\text { (6) Cognitive } \\
\text { and behavioural } \\
\text { approach }\end{array}$ & $\begin{array}{c}\text { (7) Neuroscience } \\
\text { approach }\end{array}$ \\
\hline Lund \& Kranz, 1994 & & $\checkmark$ & & $\checkmark$ & & $\checkmark$ & \\
\hline Graham, 1998 & & $\checkmark$ & $\checkmark$ & & $\checkmark$ & $\checkmark$ & \\
\hline $\begin{array}{ccc}\text { Pellitteri, } & \text { Stern } \quad \& \\
\text { Nakhutina, } 1999 & & \end{array}$ & & $\checkmark$ & $\checkmark$ & & $\checkmark$ & $\checkmark$ & \\
\hline McClung, 2000 & & $\checkmark$ & $\checkmark$ & & $\checkmark$ & $\checkmark$ & \\
\hline Kern \& Wolery, 2002 & $\checkmark$ & & $\checkmark$ & & & $\checkmark$ & \\
\hline Reimer, 2005 & & $\checkmark$ & $\checkmark$ & & & & $\checkmark$ \\
\hline $\begin{array}{l}\text { Montgomery } \\
\text { Martinson, } 2006\end{array}$ & & $\checkmark$ & $\checkmark$ & & & & $\checkmark$ \\
\hline $\begin{array}{ccc}\text { Petrides, } & \text { Niven } \quad \& \\
\text { Mouskounti, 2006 } & & \end{array}$ & & $\checkmark$ & & $\checkmark$ & $\checkmark$ & $\checkmark$ & \\
\hline Chung, 2010 & & $\checkmark$ & $\checkmark$ & & & $\checkmark$ & \\
\hline Hallam, 2010 & & $\checkmark$ & $\checkmark$ & & & $\checkmark$ & \\
\hline Hodges, 2010 & & $\checkmark$ & $\checkmark$ & & & & $\checkmark$ \\
\hline
\end{tabular}




\begin{tabular}{|c|c|c|c|c|c|c|}
\hline Goldstein, 2011 & $\checkmark$ & $\checkmark$ & & $\checkmark$ & $\checkmark$ & \\
\hline Schellenberg, 2011 & $\checkmark$ & & $\checkmark$ & $\checkmark$ & $\checkmark$ & \\
\hline Jacobi, 2012 & $\checkmark$ & $\checkmark$ & & $\checkmark$ & $\checkmark$ & \\
\hline Lamont, 2012 & $\checkmark$ & & $\checkmark$ & & $\checkmark$ & \\
\hline Overy, 2012 & $\checkmark$ & $\checkmark$ & & & & $\checkmark$ \\
\hline $\begin{array}{ll}\text { Schellenberg } & \& \\
\text { Mankarious, } 2012 & \end{array}$ & $\checkmark$ & & $\checkmark$ & $\checkmark$ & $\checkmark$ & \\
\hline Croom, 2012 & $\bar{\checkmark}$ & & $\checkmark$ & & & $\checkmark$ \\
\hline 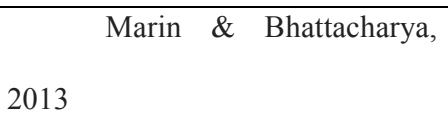 & $\checkmark$ & & $\checkmark$ & & $\checkmark$ & \\
\hline Edgar, 2013 & $\checkmark$ & $\checkmark$ & & $\checkmark$ & $\checkmark$ & \\
\hline Collins, 2013 & $\checkmark$ & $\checkmark$ & & & & $\checkmark$ \\
\hline
\end{tabular}

Table 1. Valuation criteria 


\section{Results}

The analysis of the selected studies highlights the results according to the field of study and the research approach.

\section{Correlation between playing a musical instrument and emotional development.}

Six of the articles selected explore the correlation between playing a musical instrument and emotional development. The analysis of the studies' findings takes into account the difficulty of creating items or instruments that comprehensively measure domains of ability and EI according to purely objective criteria (Petrides, Niven \& Mouskounti, 2006). We assume that this complication could lead to methodological errors in the studies' reliability in providing a comprehensive result of the effects of making music on students' emotional intelligence, and therefore their emotional skills.

Qualitative methodology was used in all six studies, which were conducted following a quasi-experimental research design. Consistent with this type of approach, the questionnaire was the most commonly used data collection instrument in all six studies. Questionnaires measured different aspects depending on the focus of the study and the domains of intelligence and emotion each one addressed. The questionnaire

topics included: IQ and emotional intelligence (Schellenberg, 2011), IQ and understanding of emotions (Schellenberg \& Mankarious, 2012), mind theory, empathy 
and emotional regulation (Goldstein, 2011), trait emotional intelligence and personality (Petrides, Niven \& Mouskounti, 2006) and flow and trait emotional intelligence (Marin \& Bhattacharya, 2013). In the last two articles, different versions of the same questionnaire were used to measure trait emotional intelligence: the Trait Emotional Intelligence Questionnaire (TEIQue-SF) by Petrides and Furnham (2006) was used in Marin \& Bhattacharya (2013), and the Trait Emotional Intelligence Questionnaire (TERIQuev) was used in Petrides, Niven and Mouskounti (2006). Furthermore, the authors of two studies (Schellenberg \& Mankarious, 2012 and Marin \& Bhattacharya, 2013) used questionnaires to collect data on demographic variables. Lamont (2012) followed a free report approach in which participants were asked to describe their strongest experiences related to music. The author gave no instructions as to whether respondents should write about their experiences of performing or listening; they were left to make their own choice.

In these studies, all subjects studied or had previously studied music. Differences in the subjects' age were presented and ranged from 7 to 35 years old. The level of musical specialisation also varied. Only one article studied piano performance students being professionally trained in specialised schools from different countries (Marin \& Bhattacharya, 2013).

Not all studies examine emotional skills or emotional intelligence per se, but they explore aspects related to these concepts. This is the case of Goldstein (2011), who 
looked at the correlations among social-cognitive skills in students attending acting or arts classes. Her study measured different skills considered to be indicators of socialcognitive skills, such as theory of mind, empathy and emotional regulation. Goldstein (2011) found that all the skills were related to emotional skills since theory of mind is the ability to understand others' thoughts and feelings, empathy is an appropriate and similar response to another's emotional state, and emotional regulation refers to the understanding and control of one's own emotions.

From a complementary position, Lamont (2012) studied the connection between musical performance and well-being, undertaking an analysis from the perspective of the hedonist and eudaemonist tradition. This author explored different aspects related to emotional skills and music performance, such as flow, identity development or sense of belonging.

The study by Schellenberg (2011) found no correlation between music training and emotional intelligence. The author affirms that visual-based and/or text-based tests of EI do not reveal any association between music lessons and EI, and although music lessons can be associated with higher cognitive performance this link may not necessarily be caused by the music per se, but may be a consequence of the nature of music teaching, which demands discipline, concentration, perseverance and other similar attitudes. Schellenberg and Mankarious (2012) also point out that the weak link between music training and emotional functioning, in both childhood and adulthood, 
may only lie in emotional understanding and may be restricted to the auditory domain. The authors call for further exploration of the link between music training and emotional functioning with instruments and tests that rely less on cognitive abilities. Both studies hypothesise that it is very difficult to develop socio-emotional skills through one-to-one lessons due to the lack of interaction with classmates, and consider that one of the reasons for this is the large amount of time students are required to spend studying alone. These authors hold that if there is a correlation, it will be between playing in ensembles and the development of socio-emotional skills.

Other studies analysed conclude that a correlation - understood from different approaches - can be observed between performing with a musical instrument and diverse traits and dimensions of emotional development. Interestingly, Marin and Bhattacharya (2013) establish a correlation between trait emotional intelligence and flow and, at the same time, between flow and the emotions expressed by piano performers during their performances. As in the above-mentioned studies, Petrides, Niven and Mouskounti (2006) claim that there is no correlation between long musical training and the development of social skills. According to these authors, this is logical because of "the absence of a relationship with the 'sociability' factor" in one-to-one music lessons (p. 105). However, there is a positive association between this aspect and intrapersonal skills, particularly well-being, self-control and emotionality. Specifically, Petrides, Niven and Mouskounti (2006) agree that training musical abilities could 
develop factors of trait EI such as self-motivation, emotional-expression and emotionality, and they might increase with longer musical training. This is the position held by most of the studies, which coincide that interpersonal skills are not as developed as intrapersonal skills because learning a musical instrument requires a great deal of self study. In this regard, there is a clear need to increase group performance and, in social contexts, to properly develop intrapersonal skills.

Lamont (2012) contributes to this claim by concluding that confirmation of identity and self-esteem in relation to music, both considered as intrapersonal skills, are developed through performing. Moreover, this author found that the participants' strongest experiences were more common when their performances were shared with others in the sense of generating social meaning. Also of note, according to Marin and Bhattacharya (2013), is the positive association observed between higher scores on trait emotional intelligence of piano students and their capacity to develop flow or optimal musical experiences, both cognitively and emotionally.

Regarding the need to develop reliable instruments to measure emotional intelligence and skills in connection with playing music, one of the main objectives of the study by Petrides, Niven and Mouskounti (2006) was to validate a questionnaire to measure the construct of trait emotional intelligence. 


\section{Relationship between brain development and music education.}

This group included studies whose main objective was to enhance the literature positing a correlation between brain development and music education. Although all the studies in this category support this statement, various specificities emerge. The three studies in this group argue that advances in neuroscience regarding musical practice should be used to improve music teaching practices. However, these works are qualitative and descriptive and their respective authors use different structures in developing the contents.

Reimer (2005) provides a personal, narrative-style defence of the importance of music education. The study is based on the premise that music training activates both brain hemispheres, which implies that cognitive and emotional parts work together towards a common goal. For this reason, making music can be a holistic activity. Furthermore, if correctly handled, music teaching can help to develop both mental and physical consciousness. This author regards teachers' awareness of the influence they have on their students' music experience through their teaching to be of paramount importance, highlighting that this experience leaves a mark on their minds for the rest of their lives.

For his part, Hodges' (2010) paper covers topics such as brain plasticity and different aspects of social learning. Each field of study follows a common methodological strategy that includes an explanation of the topic from a neuroscience 
approach, its relationship to music and finally, suggestions for developing these neuroscientific issues in music lessons in order to enhance music teaching. One of the topics that the study explores in relation to emotional skills is empathy and emotions. According to the author, learning music in groups is a good context to develop empathy because while students are learning a new concept, they are sharing a common emotional experience. Once again, the teacher appears as a crucial figure as this author argues that teachers should foster teamwork to achieve a common goal. Hodges (2010) also calls on teachers to promote equality among students, and recommends that they provide a safe, dependable environment where students feel comfortable and able to express both themselves and the music.

The third study in this group, by Collins (2013), consists of a bibliographic review to support her theory and to contribute to improving musical teaching practice. Collins' (2013) review analysed 14 articles, all of which aimed to find criteria that identify musicians and non-musicians. She concludes that positive changes are observed in both the brain function and structure of musicians who have attended an individual lesson for a musical instrument for more than two years. The author argues that this finding should be taken into account when designing music programmes.

Both Hodges (2010) and Collins (2013) find that music training boosts brain plasticity. Collins (2013), based on Gibson, Folley and Park (2009), suggests that this plasticity encourages creativity and divergent thinking. Hodges (2010) and Collins 
(2013) agree that the greatest benefits resulting from musical learning are achieved if musical activity starts in an early age.

In conclusion, it is especially noteworthy that these studies lend support to a theoretical background that can be usefully applied to improve musical teaching practice, from the neuroscience field, since they provide new and effective tools for music lessons.

\section{Development of emotional skills as an integral part of music lessons}

The four investigations in this group all use a qualitative descriptive methodology. The purpose of these studies is twofold: first, to support the importance of developing emotional skills in music lessons based on the existing literature; and second, to develop proposals to implement these skills in music lessons. Jacobi (2012), for instance, uses examples from her own experience as a teacher to articulate her approach. None of the studies addresses the work of emotional skills in music learning at conservatoires or music schools; rather, although not explicitly mentioned, they focus on primary education (Jacobi, 2012), secondary education (Edgar, 2013; Pellitteri, Stern \& Nakhutina, 1999), and both (McClung, 2000).

The results of these studies coincide in that music has a special connection with the emotional part of the self and music is therefore an appropriate vehicle for developing emotional skills, which are divided into intrapersonal skills, referring to the 
capacity to recognise and manage our own emotions appropriately, and interpersonal skills, referring to the capacity to recognise and understand what the others are feeling. Intrapersonal skills developed through music lessons include self-esteem, tolerance, responsibility, impulse control, learning to express oneself correctly, creativity or developing critical thinking. According to these studies, interpersonal skills that could be learnt include cooperation, sense of belonging, empathy and active listening.

All the guidelines the authors establish to enhance these skills are put into practice in groups, since they are designed to be applied in primary and secondary schools. However, the proposals focus on developing interpersonal and intrapersonal skills, with the exception of Jacobi (2012) who focuses entirely on the former. The most frequent activities are: (1) free improvisation, which allows the students to express their own emotions without formal conditions, (2) performance in groups, which fosters respect for others, responsibility for learning one's own part properly to enable effective group rehearsal, and the ability to listen to others' views on the performance, and (3) linking the music heard with an emotion, which fosters emotional awareness and enables the proper development of the specific vocabulary for expressing emotions. All the studies except Edgar (2013) make specific proposals to improve emotional skills, such as: 
1. Performing in a musical ensemble, making students aware of "how to take turns, how to listen to one another, and how to show mutual respect for their classmates by supporting them through mistakes" (Jacobi, 2012, p. 72).

2. Having "small groups of children work together to decide on an emotion and then create music that will express that particular emotion. The other members of the class have to try to guess what emotion is being expressed through the music" (Pellitteri, Stern \& Nakhutina, 1999, p. 28).

With the exception of Pellitteri, Stern and Nakhutina (1999), all the studies mention socio-emotional learning (SEL) as a reference for learning emotional skills. The studies are grounded on the guidelines proposed by the SEL movement that emerged in the beginnings of 1990. These guidelines are self-awareness, social awareness, decision-making responsibility, self-control and management of social relationships (CASEL, 2012). According to Edgar (2013), the literature that links SEL and music education is non-empirical and limited. This author suggests it would be desirable for music teachers to implement socio-emotional teaching through SEL, since music education and SEL are "naturally complementary" (p. 3). Jacobi (2012) further supports this assertion when she states, "imagine the possible positive effects of building SEL deliberately and purposefully into lesson objectives, instruction, and assessments, a district music curriculum, or even the National Standards for Music Education" (p. 73). 
All the studies confirm the importance to students of teachers being able to develop emotional skills well. However, some authors argue that for this development to take place efficiently, teachers should first be aware of the importance of integrating emotional skills into the music curriculum and second, be trained in the subject of emotional learning (Edgar, 2013; Pellitteri, Stern \& Nakhutina, 1999). In addition, the authors provide suggestions to help teachers address social-emotional learning in their music lessons. One of these suggestions points to the need to build a good relationship between the teacher and the student, considering that a positive connection will motivate the student to pay attention in lessons and show an interest in learning (Pellitteri, Stern \& Nakhutina, 1999). Other notable considerations include setting objectives, sequencing contents related to emotional skill development and discerning in which activities they might be applied, foreseeing how the content will be assessed and recognising and valuing students' prosocial attitudes.

In sum, the studies in this group find that active musical practice is a useful tool for developing emotional skills, which in turn contribute to enrich musical learning and promote students' interaction. To bring theory and practice together, the authors make a number of recommendations and proposals. 


\section{Benefits of playing a musical instrument}

Only one of the six studies grouped in this topic (Hallam, 2010) is a systematic review; the other five articles are descriptive investigations that use mainly interviews to gather information. The six studies all examine the benefits of musical training for the individual but from different perspectives. In Lund and Kranz (1994), the emotional episodes that accompany the performance and musical composition are understood as a cycle of creativity. Chung (2010) focuses on the development of the life skills that allow us to function in our daily lives in a balanced way.

Hallam (2010) exposes a larger frame, focusing on the impact that musical activity has on intellectual, social and personal development in children and young people. Croom's (2012) study centres on the relationship between music and wellbeing. For her part, Overy (2012) explores the most suitable methods for teaching music to beginners. Graham (1998) presents music education as an opportunity to develop creativity and divergent thinking.

According to these studies, the benefits of playing a musical instrument fall into three groups, although they all take place at the same time and are closely linked (Chóliz, 2005; Goleman, 1995):

1. Intellectual development: half of the studies exploring the benefits of music are based primarily on acquiring advantages in the intellectual field, mainly in the fields of mathematics (Hallam, 2010; Chung, 2010) and language (Hallam, 
2010; Overy, 2012). These are directly related to the cognitive abilities acquired from playing a musical instrument. One example of these skills is working rhythm, which organises musical discourse in different musical figurations following beats and constant stresses. Rhythm seems to be the most significant musical feature for achieving good mathematical performance. In fact, children who have had some instruction on rhythm instruments score higher on partwhole maths problems than those who have had piano and singing instruction (Hallam, 2010). However, this finding is only applicable to mathematics, a subject related to rhythm, because of the brain's transfer capacity, although "transfer is only likely to occur when the skills required are 'near"' (Hallam, 2010, p. 274). Another example links the development of the language region of the brain with music training (Hallam, 2010; Overy, 2012). Hallam (2010) claims that some aspects of music, such as pitch, timbre or musical speech, enhance perceptual processing systems, which enable a better understanding of the spoken word. The author stresses that the earlier children start studying a musical instrument, the greater the improvements in this field will be.

2. Personal and social development: most of the aforementioned emotional skills belong to this group. Many benefits related to personal work are derived from the demands of studying a musical instrument, specifically, concentration, perseverance, responsibility and discipline (Chung, 2010; Hallam, 2010; Lund \& 
Kranz, 1994). Furthermore, successfully performing a piece after investing a great deal of time and effort, and especially sharing it through a public performance, fosters an individual's sense of achievement, self-esteem, selfconfidence, determination, emotional and thinking control, emotion expression, and enthusiasm (Chung, 2010; Croom, 2012; Hallam, 2010; Lund \& Kranz, 1994). It is interesting to note that from a broader vision of music, not limited to music training, music helps to develop the sense of self-identity, particularly among young people, who spend an average of almost three hours a day listening to music (North, Hargreaves \& O'Neill, 2000). What is probably more important, during that time they forget their problems because they are focused on something that they like and that helps them feel good: music. In this case, music is an excellent tool for mood regulation (Hallam, 2010).

Two aspects that are also developed and linked with emotional growth are flow and creativity. These two concepts are closely connected, as creativity leads to flow (Csikszentmihalyi, 1998). Since flow is a moment of optimal experience, where concentration and enjoyment are wholly present in the activity of performance, Goleman (1995) considers it to be the most advanced example of emotional intelligence. To develop creativity in music lessons Hallam (2010) suggests introducing activities based on creativity. On this point, Graham (1998) notes that the way in which music teaching is presented determines how well 
creativity is developed. Teachers must be aware of the potential for creativity in music performance and know how to develop it. The author advises teachers not to impose musical performance guidelines, but rather to encourage students to consider different interpretive choices concerning phrasing, tempo and other markings. He also suggests that in duets students could "discuss interpretive choices and come to agreement" (Graham, 1998, p. 26). This approach allows them to develop social skills. With the exception of Lund and Kranz (1994), all the other studies in this category lend support to this question. Some of the social skills referred to above are teamwork, collaboration, respect for others, empathy and a sense of belonging; all of them are developed through creating music in a group. It is also worth noting in this vein Chung's (2010) claim that the success of a good ensemble performance entails teamwork, and this means people pursuing a shared goal and expressing and listening to individual opinions.

3. Physical development and well-being: introducing music through movement enhances children's music learning, as at early ages learning is more effective through the experience of the body. At the same time, this approach to music fosters the development of children's motor skills (Hallam, 2010; Overy, 2012). A correlation between musical practice and well-being has also been demonstrated (Chung, 2010; Croom, 2012; Hallam, 2010). In this vein, Hallam 
(2010) highlights participation in a choir as one of the options for musical engagement with the widest range of health and well-being benefits for adults. Drawing on the work of Clift, Hancox, Staricoff, and Whitmore (2008) and Stacey, Brittain and Kerr (2002), Hallam (2010) argues that the benefits of singing in a choir include:

physical relaxation and release of physical tension, emotional release and reduction of feelings of stress; a sense of happiness, positive mood, joy, elations, and feeling high; a sense of greater personal, emotional and physical well-being; an increased sense of arousal and energy, stimulation of cognitive capacities attention, concentration, memory and learning; and increased sense of selfconfidence and self-esteem; a sense of therapeutic benefit in relation to longstanding psychological and social problems; a sense of exercising systems of the body through the physical exertion involved, especially the lungs; a sense of disciplining the skeletal-muscular system through the adoption of good posture, and being engaged in a valued, meaningful worthwhile activity that gives a sense of purpose and motivation (Hallam, 2010, p. 281).

Croom (2012), in turn, argues that well-being related to performing music arises for two main reasons. The first is that performance offers the possibility to care for others; music can make musicians happy when the performance has a meaningful purpose. The second reason is that playing an instrument demands high levels of concentration and, according to Csikszentmihalyi (1990), people are happier when they are concentrating on a task; in fact it is the main requirement for experiencing flow. 
Nevertheless, not all aspects of learning a musical instrument are necessarily positive. According to Croom (2012) and Overy (2012), some issues to bear in mind include performance anxiety and potential psychosomatic problems due to frustration or physical problems derived from the posture of playing an instrument. On this latter issue, Croom (2012) claims that conservatories and music departments are now more aware of the potential risks of music performance and in consequence have created special programmes to prevent and treat music-related injuries.

\section{Music and social and emotional skills development in disabled children}

The two studies included in this category deal with music education from a therapeutic perspective. Although the proposals suggested in these investigations do not focus on formal musical teaching, they may contribute to the overall premise of this paper with several interesting ideas about enrichment and enhancement of music education for children without disabilities.

One of the two studies is an intervention (Kern \& Wolery, 2002); the other is a basic research paper (Montgomery \& Martinson, 2006). The two articles share some ideas, such as the importance of the music teacher and the music therapist working together to help disabled children achieve extra-musical skills. However, due to the idiosyncrasies of the two studies, the results of each one are discussed individually. 
Kern and Wolery (2002) conducted a case study of a three-year-old child with congenital deaf-blindness. After an intervention programme based on the child's active musical practice, the authors noted a significant improvement in his attitude and enhanced development of his communicative capacity and self-esteem. As a result he was able to better integrate with his peers, who also benefitted from the intervention.

Montgomery and Martinson's (2006) descriptive study outlines the importance of music learning for developing a series of useful life skills, namely, (1) physical abilities, through the necessary motor skills for playing a musical instrument; (2) cognitive abilities, developed through musical understanding, and (3) social and emotional abilities, achieved by performing in groups and during music lessons in general. Building on this, the authors suggest that teaching can be more effective if music education and music therapy professionals discuss and share information before designing the lessons according to the needs of each student. If the music teacher does not have the chance to work with a therapist, the authors make a number of suggestions specifically for music teachers to help them plan the sessions so as to develop students' extra musical skills.

These studies conclude that although playing music has numerous potential benefits, it should be addressed from the most appropriate perspective for each student to enable them to develop these benefits properly; this is especially true in the case of children with special needs or disabilities. The idea that music therapists and music 
teachers should work alongside each other to design specific activities is very relevant to these two studies.

\section{Conclusions}

The 21 investigations analysed have a common objective: they deal with the potential social and emotional skills to be gained from playing a musical instrument, although these skills are not always specifically mentioned. This is the main limitation of this body of research, which arises due to the lack of literature in this field. Nevertheless, the research is addressed from a variety of perspectives. Some of the studies focus on the perspective of professional musicians, others approach their inquiry from a general education perspective and others include the perspective of special education. After analysing the studies, the following issues were identified:

a) There is a lack of scientific literature based on interventions exploring the development of emotional skills in primary and secondary school music education. The only interventions identified come from the special education field where music is used as a therapeutic tool. On the other hand, several basic research studies measure and support the importance that learning a musical instrument can have for individuals, especially children. Furthermore, there is a notable absence of research exploring the role of emotional skills development in musical performance in conservatoires and music schools. 
b) Within the context of education, the teacher becomes an essential figure for the successful acquisition of socio-emotional skills. Therefore teachers must first have received adequate emotional education training, and second, they must demonstrate a positive predisposition and attitude towards working on socio-emotional content in their teaching.

c) There is a positive correlation between studying a musical instrument and the development of certain emotional skills. This correlation occurs in cases where the musical experience is positive. Intrapersonal skills are observed to be fostered by both individual and in-group musical practice, while interpersonal skills are better developed in groups.

d) Socio-emotional skills do not exist in isolation; rather, they are closely related to brain development, cognitive abilities and well-being.

e) The greatest potential benefits of music education depend on the length of the training, and research suggests that an average of least two years is required before any evidence of benefits is seen. Moreover, some studies suggest that the earlier the music student begins to play an instrument, the greater the benefits will be.

This review has identified the need to design and implement interventions aimed to develop emotional skills through music education in both primary and secondary schools. The literature on the connections between emotional skills and music training in conservatories and music schools is scarce, revealing a need for further research in 
this field to explore the effects of music learning on emotional development, and also the consequences of training emotional skills for music performance.

Consistent with suggestions retrieved from the research, interventions could be scheduled sequentially as a series of activities, including active music making, and could focus on developing emotional skills. The activities can be organised both crosssectional and specifically and need to be based on the music education curriculum. In many countries, music education has essentially been based on developing 'knowledge about' music, as this factual knowledge that sometimes is understood to be separate from the acquisition of skills (Fautley \& Murphy, 2013). Today, the idea that knowledge predominates over skills is growing and needs to be included in the debates about music education (Fautley \& Murphy, 2016). The work on the development of emotional skills in music education, consistent with a more skills-based model of educating, should therefore be considered in academic and scientific discussions. For this reason, the authors suggest that the development of emotional skills should be included in the music curriculum, and it would be beneficial for teachers and music therapists and/or psychology faculty members to undertake this task jointly.

Some examples of the activities proposed are implementing cross-sectional activities that include the use of specific nomenclature of musical expression to link with different emotional states or to create stories that match the emotion suggested by the piece of music performed. This can help students learn to recognise their emotions 
and acquire specific vocabulary to express them adequately. Creativity can be developed through specific activities such as free improvisation performance to express one's own emotions without specific patterns through the instrument. Another suggestion is to design a study timetable, with the aim of encouraging organisation, discipline and responsibility. In addition, cooperation and respect among classmates should be stimulated in order to foster interpersonal skills. A useful way of achieving this goal is to raise students' awareness of the importance of working together as it enables the group to function smoothly. The specific scientific literature in this field could thereby be revised and reinforced, and new research lines deriving from the novel ideas raised during the interventions could also be proposed.

It has also been demonstrated that some traits, including socio-cultural and genetic cognition, influence emotion. In the brain, emotion and cognition work together, making it difficult to measure the two aspects independently, which may lead to errors in the methodological approach and possibly to unreliable results. Measuring the emergence of emotions is therefore a challenge, and as a consequence it is no easy task to establish a reliable correlation between active musical practice and the acquisition of emotional skills. Given the specific characteristics of emotion, we believe that it would be useful to create specialised instruments to measure emotional skills and take into account different individual facets. 
In line with the arguments running through this paper, we believe that although music offers great benefits for young people (Hallam, 2010), adults and older people (Creech, Hallam, Gaunt, Pincas, McQueen \& Varvarigou, 2013), music students have to face and learn to cope with challenging situations when they perform music. This is another reason for applying a pedagogy that takes into account the development of emotional skills, since these skills promote aspects such as emotional control, selfesteem or self-confidence, all of which are necessary for performing music in public. This pedagogy could give students the necessary tools for successful music performance. The authors therefore consider further research in this field to be necessary.

\section{References}

Bennett, V. (1942). Music and Emotion. The Musical Quarterly, 28(4), 406-414.

Bisquerra, R. (2003). Educación emocional y competencias básicas para la vida. Revista de Investigación Educativa, 21(1), 7-43.

Bisquerra, R., \& Pérez, N. (2007). Las competencias emocionales. Educación XX1, 10, 61-82. doi: 10.5944/educxx1.1.10.297 
Chóliz Montañés, M. (2005). Psicología de la emoción: El proceso emocional. Universidad de Valencia. Consultado el 21 de Marzo de 2013, de http://www.uv.es/choliz/Proceso\%20emocional.pdf

Chung, B. (2010). Music making and the well tempered life. Understanding Our Gift, 22(4), 3-5.

Clift, S., Hancox, G., Staricoff, R., \& Whitmore, C. (2008). Singing and health: A systematic mapping and review of non-clinicla research. Sidney de Haan Research Centre for Arts and Health: Canterbury Christ Church University.

Collaborative for Academic, Social, and Emotional Learning, CASEL (2012): Effective Social and Emotional Learning Programs, Arlington, VA, KSA-Plus Communications.

Collins, A. (2013). Music education and the brain: What does it take to make a change? Applications of Research in Music Education, 32(2), 4-10. doi:10.1177/8755123313502346

Creech, A., Hallam, S., Gaunt, H., Pincas, A., McQueen, H. \& Varvarigou, M. (2013). The power of music in lives of older people. Research Studies in Music Education, 35(1), 87-102. doi:10.1177/1321103X13478862

Croom, A. M. (2012). Music, neuroscience, and the psychology of well-being: A précis. Frontiers in Psychology, 2(393). doi:10.3389/fpsyg.2011.00393 
Csikszentmihalyi, M. (1998). Creatividad: El fluir y la psicología del descubrimiento y la invención. Barcelona: Ediciones Paidós Ibérica, S. A.

Edgar, S. N. (2013). Introducing social emotional learning to music education professional development. Applications of Research in Music Education, 31(2), 28-36. doi:10.1177/8755123313480508

Elliott, D. (2005). Musical understanding, musical works, and emotional expression: Implications for education. Educational Philosophy and Theory, 37(1), 93-103. doi:10.1111/j.1469-5812.2005.00100.x

Fautley, M., \& Murphy, R. (2013). Editorial. British Journal of Music Education, 30(2), 157-159. doi:10.1017/S0265051713000168

Fautley, M., \& Murphy, R. (2016). The nature of music itself, and the knowledge versus skills debate in music education. British Journal of Music Education, 33(2), 129132. doi:10.1017/S026505171600022X

Fernández-Berrocal, P., \& Extremera, N. (2002). La inteligencia emocional como una habilidad esencial en la escuela. Revista Iberoamericana de Educación, 29(1), 16.

Gibson, C., Folley, B. S. \& Park, S. (2009). Enhance divergent thinking and creativiy in musicians: A behavioral and near-infrared spectroscopy study. Brain and Cognition, 69(1), 162-169. 
Goldstein, T. R. (2011). Correlations among social-cognitive skills in adolescents involved in acting or arts classes. Mind, Brain and Education, 5(2), 97-103.

Goleman, D. (1995). Emotional Intelligence, Bantam Books, New York, NY.

Graham, D. (1998). Teaching for creativity in music performance. Music Educators Journal, 84(5), 24-28. doi:10.2307/3399126

Greenspan, S. I. (1989). Emotional intelligence. In K. Field, B. J. Cohler, \& G. Wool (Eds.), Learning and education: psychoanalytic perspectives (pp. 209-243). Madison, CT: International Universities Press.

Hallam, S. (2010). The power of music: Its impact on the intellectual, social and personal development of children and young people. International Journal of Music Education, 28(3), 269-289. doi:10.1177/0255761410370658

Harnoncourt, N. (1988). Baroque Music Today: Music as Speech. Ways to a New Understanding of Music. Portland, Ore.: Amadeus Press.

Hodges, D. A. (2010). Can neuroscience help us do a better job of teaching music? General Music Today, 23(2), 3-12. doi:10.1177/1048371309349569

Jacobi, B. S. (2012). Opportunities for socioemotional learning in music classrooms. Music Educators Journal, 99(2), 68-74. doi:10.1177/1048371309349569

Juslin, P. N. (2003). Five facets of musical expression: A psychologist's perspective on music performance. Psychology of Music, 31(3), 273-302. doi:10.1177/03057356030313003 
Kern, P., \& Wolery, M. (2002). The sound path: Adding music to a child care playground. Young Exceptional Children, 5(3), 12-20. doi:10.1177/109625060200500302

Lamont, A. (2012). Emotion, engagement and meaning in strong experiences of music performance. Psychology of Music, 40(5), 574-594. doi:10.1177/0305735612448510

Leuner, B. (1966). Emotionale intelligenz und emanzipation (Emotional intelligence and emancipation). Praxis der Kinderpsychologie und Kinderpsychiatry, 15, 196-203.

Lund, N. L., \& Kranz, P. L. (1994). Notes on emotional components of musical creativity and performance. The Journal of psychology, 128(6), 635-640. doi:10.1080/00223980.1994.9921291

Marin, M. M., \& Bhattacharya, J. (2013). Getting into the musical zone: Trait emotional intelligence and amount of practice predict flow in pianists. Frontiers in Psychology, 4(853), 1-14. doi:10.3389/fpsyg.2013.00853

McClung, A. C. (2000). Extramusical skills in the music classroom. Music Educators Journal, 86(5), 37-42. doi:10.2307/3399635

Meyer, L. B. (1956). Emotion and Meaning in Music. Chicago: The University of Chicago Press. 
Moher, D., Liberati, A., Tetzlaff, J., \& Altman, D. G. (2009). Preferred reporting items for systematic reviews and meta-analyses: The PRISMA statement.BMJ, 21, 331: b2535. doi:10.1136/bmj.b2535

Montgomery, J., \& Martinson, A. (2006). Partnering with music therapist: A model for addressing students' musical and extramusical goals. Music Educators Journal, 92(4), 34-39. doi:10.2307/3399635

North, A. C., Hargreaves, D. J. \& O’Neill, S. A. (2000). The importance of music to adolescents. British Journal of Educational Psychology, 70(2), 255-272. doi:10.1348/000709900158083

Overy, K. (2012) Making music in a group: Synchronization and shared experience. Annals of the New York Academy of Sciences, 1252 ,65-68. doi:10.1111/j.1749$6632.2012 .06530 . \mathrm{x}$

Pellitteri, J., Stern, R., \& Nakhutina, L. (1999). Music: The sounds of emotional intelligence. Voices from the Middle, 7(1), 25-29.

Petrides, K. V., \& Furnham, A. (2006). The role of trait emotional intelligence in a gender-specific model variables. Journal of Applied Social. Psycholy, 36(2), 552-569. doi:10.1111/j.0021-9029.2006.00019.x

Petrides, K. V., Niven, L., \& Mouskounti, T. (2006). The trait emotional intelligence of ballet dancers and musicians. Psicothema, 18(SUPPL.1), 101-107.

Rachmawati, Y. (2010). The role of music in character building. International Journal 
of Learning, 17(9), 61-76.

Reimer, B. (2005). New brain research on emotion and feelings: Dramatic implications for Music Education. Arts Education Policy Review, 106(2), 21-27.

Resnicow, J. E., Salovey, P., \& Repp, B. H. (2004). Is recognition of emotion in music performance an aspect of emotional intelligence. Music Perception, 22(1), 145158.

Salappa-Liopoulou, A. (2012). Music Evolution in Ancient Greece and the Value of Music Education in Pseudo-Plutarch's De Musica. Schole: Journal of Centre for Ancient Philosophy and the Classical Tradition, 6(1), 76-86.

Salovey, P., \& Mayer, J. D. (1990). Emotional intelligence. Imagination, Cognition and Personality, 9, 185-211. doi:10.2190/DUGG-P24E-52WK-6CDG

Sastre, P. M. (2014). La Inteligencia Emocional en el Aprendizaje de los Alumnos de Enseñanzas de Régimen Especial en los Conservatorios de Música. DEDICA. Revista de Educaçao E Humanidades, 6, 187-198.

Schellenberg, E. G. (2011). Music lessons, emotional intelligence, and IQ. Music Perception, 29(2), 185-194. doi:10.1525/mp.2011.29.2.185

Schellenberg, E. G., \& Mankarious, M. (2012). Music training and emotion comprehension in childhood. Emotion, 12(5), 887-891. doi:10.1037/a0027971

Stacey, R., Brittain, K., \& Kerr, S. (2002). Singing for health: An exploration of the issues. Health Education, 102(4), 156-162. doi:10.1177/0255761410370658 
